九州大学学術情報リポジトリ

Kyushu University Institutional Repository

\title{
Morphological Analysis of Eggshell in the Shirotae-ran Mutant, vit, Bombyx mori
}

Fuj ikawa, Kazuhiro

Laboratory of Sericultural Science and Institute of Genetic Resources, Faculty of Agriculture, Kyushu University

\section{Kawaguchi, Yutaka}

Laboratory of Sericultural Science and Institute of Genetic Resources, Faculty of Agriculture, Kyushu University

\section{Banno, Yutaka}

Laboratory of Sericultural Science and Institute of Genetic Resources, Faculty of Agriculture, Kyushu University

Koga, Katsumi

Laboratory of Sericultural Science and Institute of Genetic Resources, Faculty of Agriculture, Kyushu University

他

https://doi.org/10.5109/24132

出版情報：九州大学大学院農学研究院紀要. 41 (1/2)，pp.75-81，1996-11. Kyushu University バージョン：

権利関係 : 
J.Fac. Agr., Kyushu Univ., 41(1·2),75-81(1996)

\title{
Morphological Analysis of Eggshell in the Shirotae-ran Mutant, vit, Bombyx mori
}

\author{
Kazuhiro Fujikawa, Yutaka Kawaguchi*, Yutaka Banno, \\ Katsumi Koga and Hiroshi Doira
}

\author{
Laboratory of Sericultural Science and Institute of Genetic Resources, \\ Faculty of Agriculture, Kyushu University, Fukuoka 812-81, Japan \\ (Received July 31, 1996)
}

\begin{abstract}
The morphology of the eggshell (chorion) of the shirotae-ran mutant, vit (wherein the yolky substances are poor), of Bombyxmori was observed by scanning electron microscopy and differential interference contrast microscopy. The egg size was slightly smaller in the mutant than in the normal. The surface structures of the micropyle in the anterior pole region and the basic patterns of the network structures (polygons) imprinted on the lateral flat surfaces as well as the mode of distribution of the small knobs in the posterior, ventral and dorsal regions exhibited no peculiarity in the mutant. The polygons were significantly smaller in si ze in the mutant than in the normal. However, the number of polygons per whole lateral side did not differ between the mutant and the normal. The cross section of the mutant chorion was as usual in terms of layer structure and thickness. These findings imply that the choriogenesis occurs ordinarily in the vit mutant.
\end{abstract}

\section{INTRODUCTION}

The egg characters of Bombyx mori have been investigated with respect to the size, shape and color of eggshell, properties of serosa, the content and component of yolky substances, developmental aspects of oocytes and embryos etc. (Doira et al., 1992). We found a novel egg mutant which was artificially generated by treating normal B. mori eggs with N-methyl-N-nitrosourea. This mutant was named the "shirotae-ran" since the eggs are pure white in color and the yolky substances in particular vitellin are poor in content (Fujikawa et al., 1993b; 1995). The embryos are sterile. Genetical analysis showed that the characters of this mutant are controlled by a single recessive gene which is inscribed the "scanty vitellin" with the symbol vit (Fujikawa et al., 1993a). The gene responsible for this mutation was located at 23.0 of the 20th chromosomal linkage group (Fujikawa et al., 1996). In the present study we observed morphologically the size, shape and the surface structures of the mutant eggs in comparison with the normal eggs. Also the cross sections of eggshells were observed for the chorion layer structures.

\section{MATERIALS AND METHODS}

\section{The strain used and the mode of mating}

The vit strain $\mathrm{d} 50$ maintained in the Institute of Genetic Resources, Kyushu University, was used. This strain carries the hoarfrost allele (symbol, oh), as a marker,

* Corresponding author. 
belonging to the same linkage group as vit. After the mating $++/$ oh vit (females) $x o h$ vitloh vit (males), oh heterozygotes with the normal skin character and oh homozygotes with the oily skin character were segregated within the same batch; the former produced normal eggs while the latter vit eggs, i.e., shirotae-ran. Both types of eggs having the common genetic background were compared in the present study.

\section{Morphological observations of eggshells}

Mature eggs were dissected from unmated female adults and washed with distilled water. The whole eggs were fixed in Carnoy's fluid for 3 or 4 days at $0{ }^{\circ} \mathrm{C}$, dehydrated in a graded ethanol series, freeze dried with tert-butyl alcohol, mounted on a stub with double-stick carbon tape, sputter coated with gold and subjected to scanning electron microscopy (SEM) using a JSM5200 to observe the central parts of anterior, posterior, dorsal, ventral and lateral regions of an eggshell surface. To observe the chorion layer structures the eggs were immersed in distilled water, ripped with fine watchmaker's forceps and then the fragments were processed as above and subjected to SEM. To measure the areas of the network patterns (polygons) of eggshells, the eggs were cut with a razor blade and the chorion fragments were washed with distilled water and mounted on a slide. The central parts of lateral regions of eggshell surface were observed by interference microscopy using Zeiss Axioplan equipments. The average areas were calculated as described previously (Kawamura and Nakada, 1981; Kawaguchi et al ., 1993).

\section{RESULTS}

\section{Size and shape of eggs}

The side view was laterally flattened ellipsoidal in the normal mature egg and there was no difference in the vit mutant egg (Fig. 1A and B). The lengths of the major and minor axes were $1.26 \pm 0.03 \mathrm{~mm}$ and $1.04 \pm 0.04 \mathrm{~mm}$, respectively, in the normal, while these were $1.14 \pm 0.04 \mathrm{~mm}$ and $0.88 \pm 0.06 \mathrm{~mm}$, respectively, in the mutant. The size of the mutant egg was significantly smaller than that of the normal egg, although the difference was not extensive.

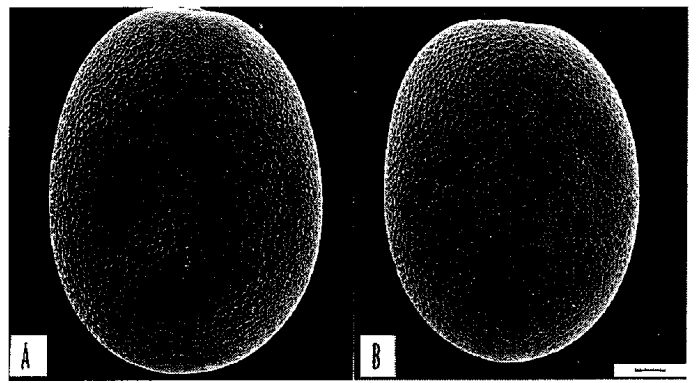

Fig. 1. Lateral flat side views of eggshells, each with the anterior pole region at the top and ventral side region at the left. A, Normal; B, mutant. Scale bar $=0.1 \mathrm{~mm}$. 


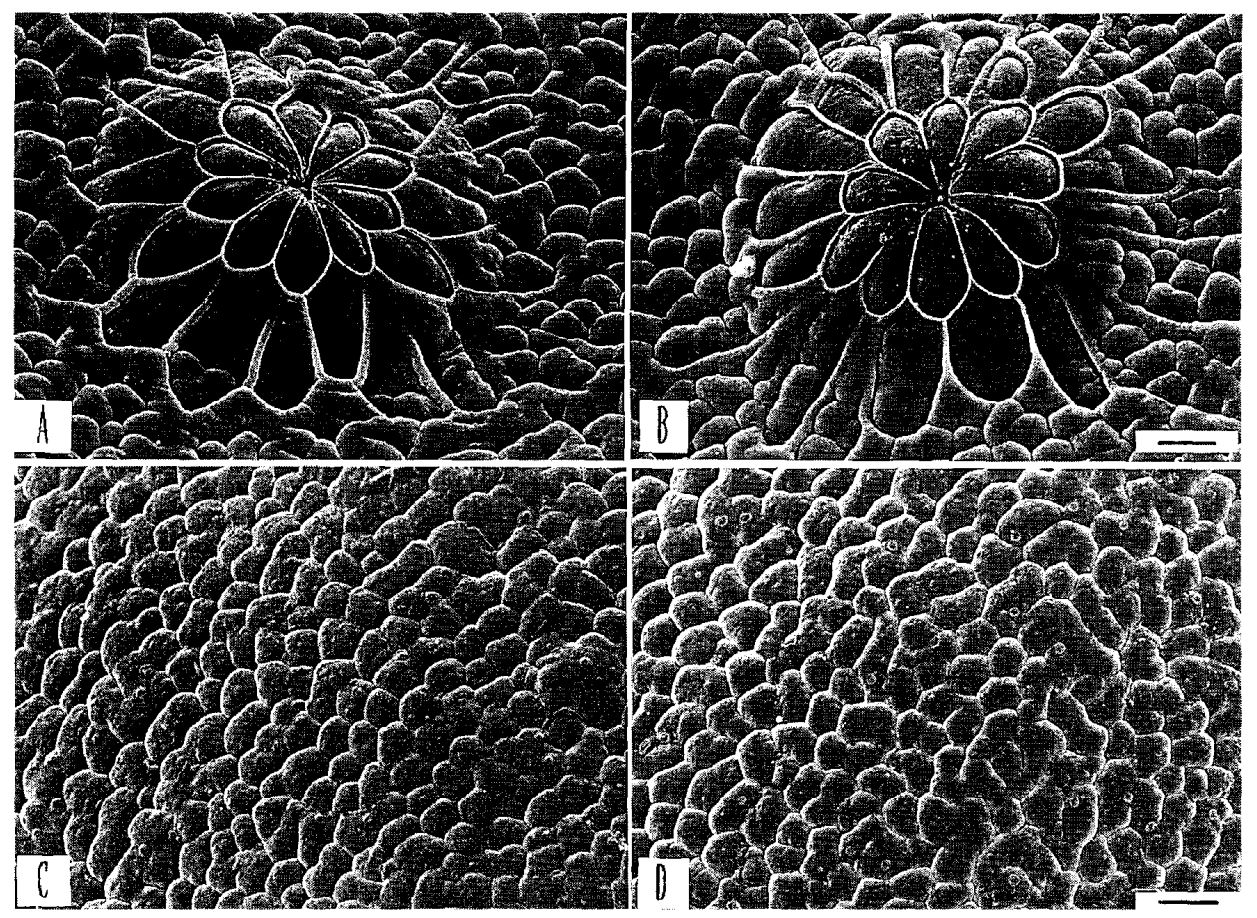

Fig. 2. Surface structure of the anterior $(A$ and $B)$ and posterior $(C$ and $D)$ pole regions of eggshell under a scanning electron microscope (SEM) A and $\mathrm{C}$, normal; B and D, mutant. Scale bar $=10$ j. $\mathrm{m}$

\section{Observation of anterior and posterior pole regions}

The anterior pole region has the micropyle, a single external opening for the entrance of sperms. The opening is surrounded by petal-shaped imprints making a double-petaled rosette. The shape made by the micropyle and rosette was the same in the normal and mutant eggs (Fig. 2A and B). On the surface of the posterior region, there are numerous small granule-like knobs, which have large and small aeropyles. These features of the structure at the posterior region in the normal and the mutant were quite similar to each other (Fig. 2C and D).

\section{Observation of the dorsal, ventral and lateral regions}

The knobs with aeropyles, like those shown above, are also seen in the dorsal and ventral regions, and the structures were similar between the normal and the mutant (Fig. $3 \mathrm{~A}$ and $\mathrm{B}, \mathrm{E}$ and $\mathrm{F}$ ). The two flat lateral surfaces of an eggshell are filled with network patterns called the polygons (Fig. 3C and D), each corresponding to the secretory surface of a single follicle cell. The boundary of the polygons makes a ridge, reflecting a two-cell junction. The inner hole of every polygon has several small knobs. The area of each polygon in the mutant was significantly smaller than that in the normal (Table 1), althohgh there were no specific features of polygon patterns in the mutant. Also little difference was found in the mutant with respect to the number of polygons per whole 


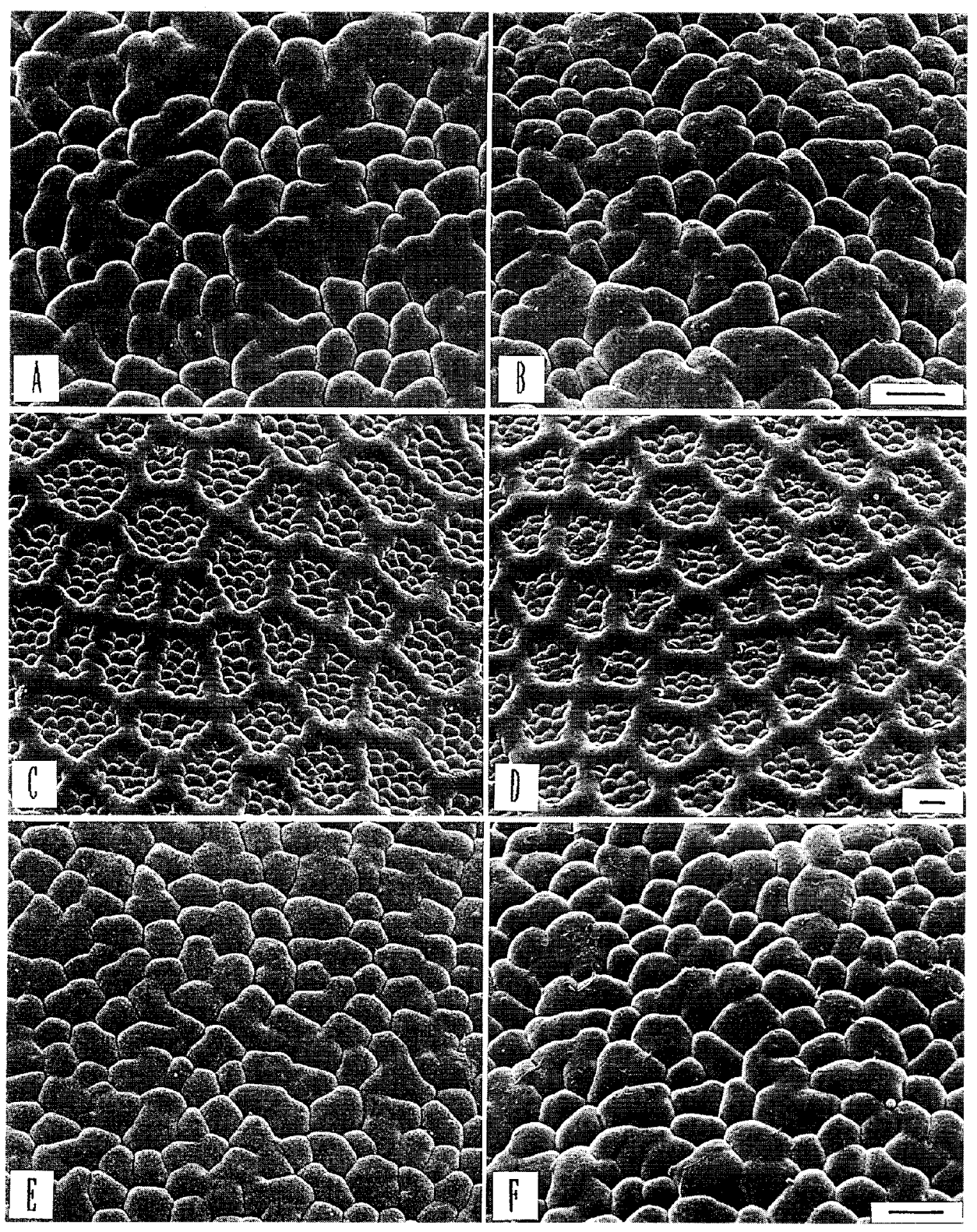

Fig. 3. Surface structure at the dorsal (A and $B)$, lateral (C and $D)$, and ventral $(\mathrm{E}$ and $\mathrm{F})$ side regions of eggshells under an SEM. A, C and $\mathrm{E}$, normal; B, D and F, mutant. Scale bar $=10 \mathrm{pm}$. 
Table 1. Areas of polygons in the lateral flat region of an egg taken from the oviducts of newly emerged females.

\begin{tabular}{lccc}
\hline $\begin{array}{l}\text { Phenotype } \\
\text { eggs }\end{array}$ & $\begin{array}{c}\text { No. of } \\
\text { polygons }\end{array}$ & $\begin{array}{c}\text { Area of polygon') } \\
\left(\mu \mathrm{m}^{2}\right)\end{array}$ \\
\hline $\begin{array}{l}\text { Normal } \\
\text { vit }\end{array}$ & 15 & 450 & $681.4 \pm 63.3$ \\
& 450 & $517.7 \pm 38.4^{*}$ \\
b) Photographs of the surfaces at the lateral flat regions of eggshells \\
were taken through a differential interference contrast microscope \\
and used for calculation. \\
* Significant at 1\% level.
\end{tabular}

Table 2. The number of polygons per whole lateral flat region at one side of an eggshell.

\begin{tabular}{lcc}
\hline $\begin{array}{c}\text { Phenotype } \\
\text { eggs }\end{array}$ & $\begin{array}{c}\text { No. of } \\
\text { polygons }\end{array}$ \\
\hline Normal & 15 & $1,457 \pm 131$ \\
vit & 15 & $1,456 \pm 111^{\prime \prime \prime}$ \\
n.s Difference statistically insignificant &
\end{tabular}

lateral side of an eggshell (Table 2), indicating that the total number of follicular epithelial cells per egg was not affected by the mutation.

\section{Observation of cross-sectional structure of the chorion}

The internal structure of the chorion in the lateral flat regions was visualized using cross-sectioned specimens. Three layers could be discriminated in both of the normal and mutant (Fig. 4A and B). The inner layer, which was the thinnest, consists of small columns oriented perpendicularly to the oocyte surface. The middle layer, having regular and parallel lamella, is the thickest and occupies most of the chorion layer. The outer layer reveals a lamellate, smooth and hard crust which is compactly integrated with a thinner strata. Difference in the laminal structure of the chorion was scarce between the normal and the mutant. Using the photographs the thickness of the chorion layer in the lateral region was measured. Again no distinctness was found in the mutant (Table 3).

Table 3. The thickness of chorion in lateral side region of eggshell.

\begin{tabular}{ccc} 
Phenotype & $\begin{array}{c}\text { No. of } \\
\text { eggs }\end{array}$ & $\begin{array}{c}\text { Thickness of } \\
\text { chorion }(\mu \mathrm{m})\end{array}$ \\
Normal & 15 & $17.8 \mathrm{i} 2.4$ \\
vit & 15 & $16.3-\mathrm{t} 1.5^{\prime \prime \prime}$ \\
\hline
\end{tabular}

ns. Difference statistically insignificant. 


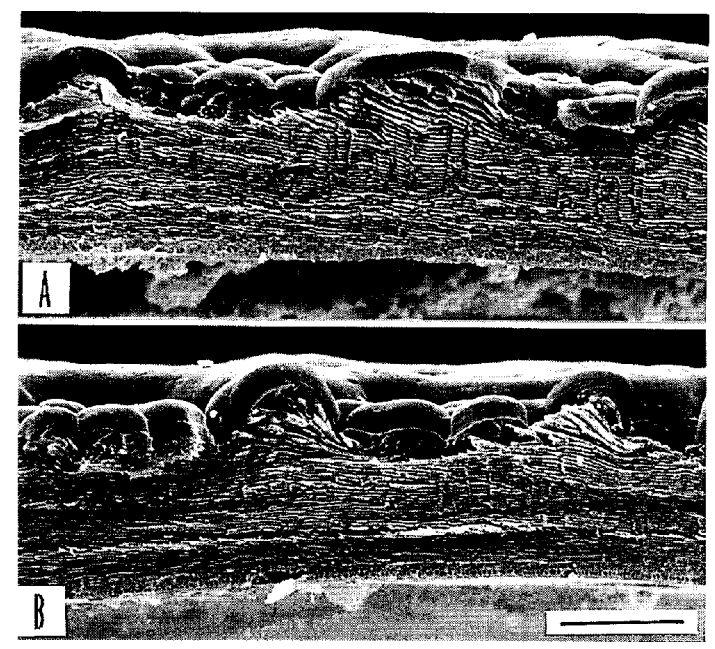

Fig. 4. Sectional structure at lateral flat regions of eggshells under an SEM. A, normal; B, mutant. Scale bar $=10 \mu \mathrm{m}$.

\section{DISCUSSION}

The chorion of insects is composed of proteins which are synthesized and secreted by the follicular epithelial cells (for B. mori cf. Matsuzaki, 1968; Bock et al., 1986). Therefore, the surface structure of the eggshell is determined by the secretory activities of these cells (Omura and Kataoka, 1943). In the present study, we observed the surface structures of the B.mori chorion, discriminating the four spatially differentiated regions 1) anterior pole (micropyle region), 2) posterior pole, 3) dorsal plus ventral and 4) lateral flat sides regions as has been done in previous studies (Sakaguchi et al., 1973; Kanda et al., 1974; Akai, 1976; Ohtsuki et al., 1977a, b; Ohtsuki and Kanda, 1978; Mazur et al., 1980; Regier et al., 1980; Katsuno, 1984a, b). The surface structures at these four regions, and also the layer structures seen in the cross section, were quite normal in the vit eggs. Moreover, the number per whole lateral area of the follicular epithelial cells forming the chorion proteins was regular in the mutant. Although the egg size and the polygonal area in the mutant were to a certain extent smaller compared with the normal values, implying that each of the follicular epithelial cells in the mutant is small, we conclude that the vit gene scarcely affects the process of eggshell formation.

\section{ACKNOWLEDGEMENT}

This study was supported in part by a Grand-in-Aid for Scientific Research (Nos. 07406004 and 08406006) from the Ministry of Education, Science and Culture of Japan. 


\section{REFERENCES}

Akai H. 1976 Surface Structure of Insects. University of Tokyo Press, Tokyo, pp. 122-127

Bock S.C., K. Campo and M.R. Goldsmith 1986 Specific protein synthesis in cellular differentiation. VI. Temporal expression of chorion gene families in Bombyx mori strain C101. Develop. Biol., 117: 215 225

Doira H, H. Fujii, Y. Kawaguchi, H. Kihara and Y. Banno 1992 Genetical Stocks and Mutations of Bombyx mori: Important Genetic Resources - 1992-. Institute of Genetic Resources, Faculty of Agriculture, Kyushu University, Fukuoka, 73 pp.

Fujikawa K., Y. Kawaguchi, Y. Banno, H. Doira and K. Koga 1993a Inheritance of a new mutant "shirotaeran" in Bombyx mori.J. Seric. Sci., Jpn. 62: 88-90

Fujikawa K., Y. Kawaguchi, Y. Banno,S. Akagi and K. Koga 1993b Characteristics of the vit mutant egg in Bombyx mori. J. Seric. Sci. Jpn., 62: 286-291

Fujikawa K., Y. Kawaguchi, Y. Banno, K. Koga and H. Doira 1995 Yolk of a "scanty vitellin" mutant, vit, of Bombyx mori is lacking in vitellin and $30 \mathrm{kDa}$ proteins. Comp. Biochem. Physiol., 112A: 585-589

Fujikawa K., Y. Kawaguchi, Y. Banno, H. Doira and K. Koga 1996 Linkage studies on the "scanty vitellin" egg mutant of Bombyx mori. J. Seric. Sci., Jpn. 65: 145-146

Kanda T., H. Matsumura and Y. Ohtsuki 1974 Surface structure of silkworm (Bombyx mori) egg. I. Fine structure of micropylar apparatus. J. Seric. Sci. Jpn., 43: 379-383

Katsuno S. 1984a Size of polygonal patterns of the egg-shell and facets of the compound eye in the tetraploid silkworm, Bombyx mori. J.Seric. Sci. Jpn., 53: 1-6

Katsuno S. 1984b Surface structure of the egg-shell in polyploid silkworm, Bombyx mori. J. Seric. Sci. Jpn., 53: 97-107

Kawaguchi Y., Y. Banno, K. Koga, H. Doira and H. Fujii 1993 Polygonal patterns on eggshells of giant egg mutant and large eggs induced by 20-hydroxyecdysone in Bombyx mori.J. Insect Physiol., 39: 437443

Kawamura N. and T. Nakada 1981 Studies on the increase in egg size in tetraploid silkworms induced from a normal and a giant egg strains. Jpn. J. Genet., 56: 249-256

Matsuzaki M. 1968 Electron microscopic observation on chorion formation of the silkworm, Bombyx mori. J. Seric. Sci. Jpn., 37, 483-490

Mazur G.D., J.K. Regier and F.C. Kafatos 1980 The silkmoth chorion: Morphogenesis of surface structures and its relation to synthesis of specific proteins. Develop. Biol., 76: 305-321

Ohtsuki Y., T. Kanda. and H. Matsumura 1977a Surface structure of silkworm (Bombyx mori) egg. II. Characteristics of different of egg surface. J. Seric. Sci. Jpn., 46: 45-50

Ohtsuki Y., T. Kitazawa and T. Kanda 1977b In vitro formation of egg shell in the silkworm (Bombyx mori).Zool. Mag., 86: 168-173

Ohtsuki Y. and T. Kanda 1978 Characteristics structure of egg shell in the collapsing egg strain of the silkworm. J.Seric. Sci.Jpn., 47: 215-220

Omura S. and T. Kataoka 1943 Shape, sizes and their formation of the surface pattern of the egg-shell in Bombyx mori and Bombyx mandarina. J. Seric Sci. Jpn., 14: 263-275

Regier J.C., G.D. Mazur and F.C. Kafatos 1980 The silkmoth chorion: Morphological and biochemical characterization of four surface regions. Develop. Biol., 76: 286-304

Sakaguchi B., H. Chikushi and H. Doira 1973 Observation of the eggshell structures controlled by gene action in Bombyx mori.J.Fac. Agric. Kyushu Univ., 18: 53-62 